\title{
Overlaying welding technology and performance of axle tube remanufacturing
}

\author{
Shou-Xu Song • Yun-Dong Liu $\cdot$ Qing-Di Ke • \\ Ye-Chao Shen
}

Received: 3 April 2013/Accepted: 28 April 2013/Published online: 11 May 2013

(C) Shanghai University and Springer-Verlag Berlin Heidelberg 2013

\begin{abstract}
Screw failure is one of the main scrap forms for rear axle tube, and thread turning after surfacing is a common means of remanufacturing. This paper takes rear axle tube as the main research topic, which is made of $40 \mathrm{Mn}$ and provided by an axle company. Manual electric arc welding, $\mathrm{CO}_{2}$ shielded arc welding and argon shielded arc welding are carried to overlay the damaged thread. The deposited metal consists of two welding material lays. Welding process and overlay properties are characterized by the test and analysis of microstructure, residual stress and hardness of surfacing layers. The results show that argon shielded arc welding is an effective method to repair the failure thread; its microstructure of fusion area is meticulous and uniform; its residual compressive stress (absolute value) of welding surface is the biggest among the three welding methods; its hardness curve is relatively flat and appropriate for turning.
\end{abstract}

Keywords Surfacing $\cdot$ Remanufacturing $\cdot$ Metallographic structure $\cdot$ Residual stress $\cdot$ Hardness

\section{Introduction}

As the terminal assembled components of automotive transmission system, rear axle is an important part, but often breaks down due to various reasons. On the basis of statistical analysis report of failure drive axles which was submitted by a domestic automobile plant, the damaged thread accounts for $13.6 \%$ of the failure drive axles, which

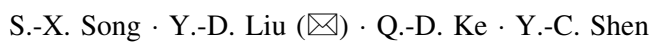

School of Mechanical and Auto Engineering, Hefei University

of Technology, Hefei 230009, People's Republic of China

e-mail: liuyundongok@126.com caused a great loss to the automobile plant. It is well known that remanufacturing engineering is an important way to develop circular economy, save energy and reduce emission. It can make waste resources obtain the maximum limit development [1-4]. Therefore, the study of rear axle remanufacture is of great practical significance.

For the failure thread of rear axle tube, repairing thread is the main method for rear axle remanufacturing. The common method in the traditional process is to repair failure thread, such as thread turning after surfacing, replacing screw thread with a new thread structure and making a new thread repairs by repairing match means. As for repairing the thread of rear axle tube, different types of rear axle tube have different maintenance methods. For example, replacing the axle tube is the best way for molten rear axle, and thread turning after surfacing is a common method for the one by welding after stamping [5-7]. However, there are still many problems for the last one. For instance, the hardness of welding material is usually too high to lathe. At the same time, the bonding strength between welding material and parent metal is low and often produces various welding defects. As the fine thread, screw of axle tube is easily damaged during the wheel hub maintenance. Therefore, it has great practical significance to discuss welding process and overlay properties for rear axle tube remanufacture.

\section{Experimental technology and method}

2.1 Technological parameter and method for the preparation of deposited metal

The waste axle tubes provided by an axle company are used for base metal (see Fig. 1). The surfacing place is the 
dimensioning position in Fig. 1, which should be sanded to remove rust and eliminate crack. Table 1 shows the elementary composition of base metal, electrode J422 and solder wire ER50-6.

\subsubsection{Electric arc welding for the preparation of deposited metal}

Overlay equipment type is BX1-330 alternative current welder. Electrode model is J422. Its diameter is $3.2 \mathrm{~mm}$. Welding electric current is $100 \mathrm{~A}$. Two layers along the axis of axle tube are welded. To guarantee interpass temperature, the second weld overlay should be down after an appropriate length of time when the first overlay has been completed.

\subsection{2 $\mathrm{CO}_{2}$ shielded arc welding for the preparation of deposited metal}

Overlay equipment type is KRII500 gas-shielded welding machine. Solder wire is ER50-6. Its diameter is $1.6 \mathrm{~mm}$. Welding electric current is $200 \mathrm{~A}$. Welding voltage is $30 \mathrm{~V}$. Adopt DC reverse connection. Flow rate of $\mathrm{CO}_{2}$ is $12-18 \mathrm{~L} / \mathrm{min}$.

\subsubsection{Argon shielded arc welding for the preparation of deposited metal}

Apart from replacing $\mathrm{CO}_{2}$ with argon, its overlay equipment and technological parameter are the same as $\mathrm{CO}_{2}$ shielded arc welding.

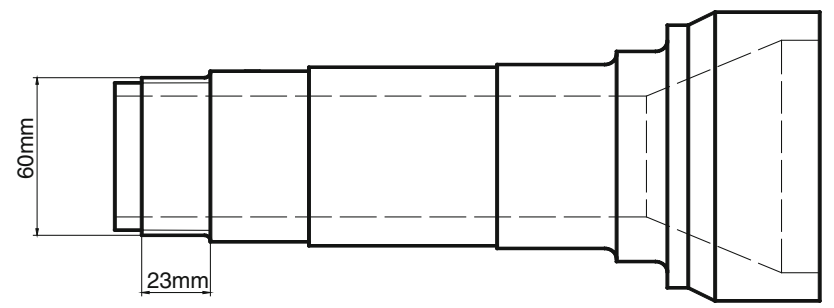

Fig. 1 Structure of axle tube

\subsection{Testing instruments and methods}

\subsubsection{Detection of residual stress}

The transverse and longitudinal stress for the layers of overlaying welding with proto residual stress analyzer is tested. Four detected regions are distributed evenly along the circumference, and each region includes four inspection points. The final value of transverse and longitudinal residual stress is the average of 16 measurements. According to ASTM E915-90, the basic testing parameters are set up as flows. The test mode is omega method. $K$ alpha ray of $\mathrm{Cr}$ target is used. Its working voltage is $20 \mathrm{kV}$, and working current is $4 \mathrm{~mA}$. Beta angle is $30^{\circ}$. (211) crystal plane is tested. Bragg angle is $156^{\circ}$. The aperture diameter of light is $1 \mathrm{~mm}$. Exposure time is $1 \mathrm{~s}$. Peak fit method is Pearson.

\subsubsection{Test of microstructure and hardness}

Test pieces are processed by wire cut electrical discharge machining (see Figs. 2-4). Polishing process should be done before the test of metallographic structure. The structure of morphology is detected by JSM-6490LV scanning electron microscope. Vickers hardness is tested by HVS-50Z microscope hardness tester. Its applied load is $49.03 \mathrm{~N}$, and load time is $5 \mathrm{~s}$ Hardness test layers are distributed evenly from outmost welding layer to base metal, and each detection layer is placed per $0.5 \mathrm{~mm}$. Each

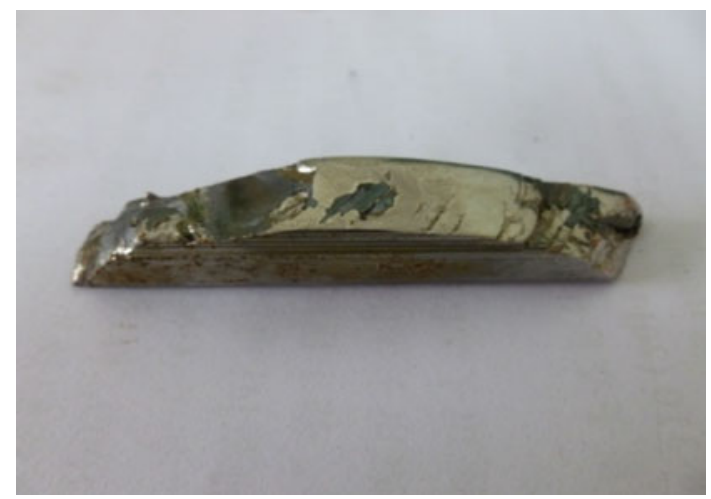

Fig. 2 Test piece of electric arc welding

Table 1 Elementary composition of base metal, electrode J422 and solder wire ER50-6 \%

\begin{tabular}{|c|c|c|c|c|c|c|c|c|}
\hline \multirow[t]{2}{*}{ Material } & \multicolumn{8}{|l|}{ Element } \\
\hline & $\mathrm{C}$ & $\mathrm{Si}$ & $\mathrm{Mn}$ & S & $\mathrm{P}$ & $\mathrm{Cr}$ & $\mathrm{Ni}$ & $\mathrm{Cu}$ \\
\hline $40 \mathrm{Mn}$ & $0.37-0.45$ & $0.17-0.37$ & $0.70-1.00$ & $\leq 0.035$ & $\leq 0.035$ & $\leq 0.25$ & $\leq 0.30$ & $\leq 0.25$ \\
\hline $\mathrm{J} 422$ & $\leq 0.3$ & $\leq 0.18$ & 0.31 & $\leq 0.035$ & $\leq 0.040$ & & & \\
\hline ER50-6 & $0.06-0.15$ & $0.80-1.15$ & $1.40-1.85$ & 0.025 & 0.025 & & & \\
\hline
\end{tabular}




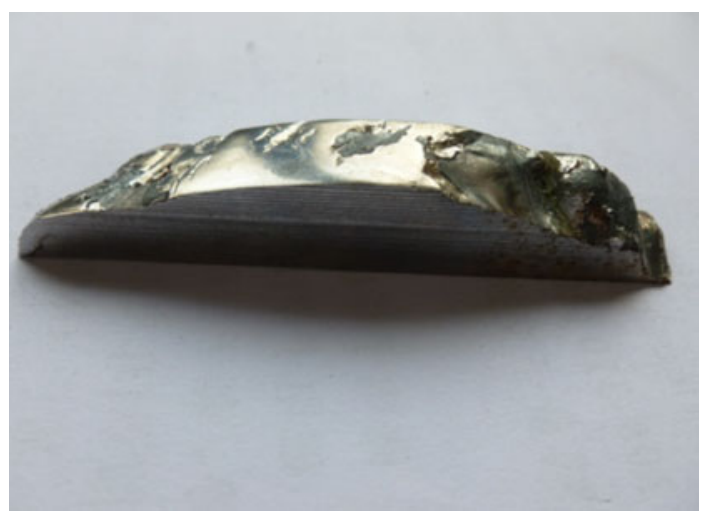

Fig. 3 Test piece of $\mathrm{CO}_{2}$ shielded arc welding

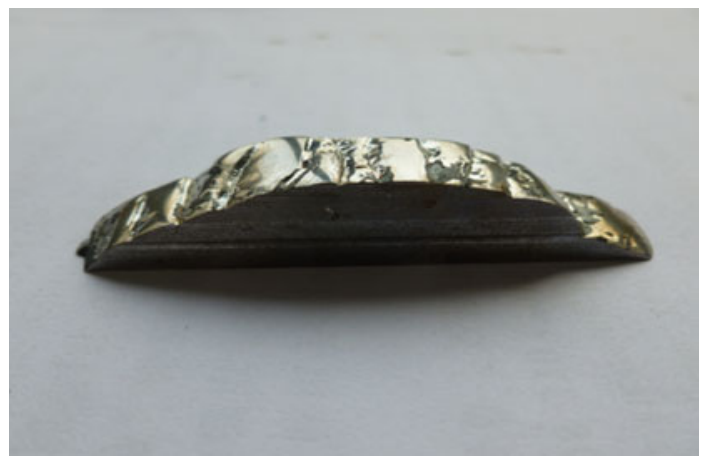

Fig. 4 Test piece of argon shielded arc welding

layer includes three control points. The hardness value of each layer is the average of three measurements.

\section{Results and discussion}

\subsection{Analysis of metallographic structure}

Fusion zone is the weak area of welded joint, which features un-uniformity chemical composition and more microstructure defects such as cold cracking, reheat cracking and brittle phase [8].

Figure 5 shows the microscopic structure of $40 \mathrm{Mn}$ base metal. Gray massive microstructure is ferrite, which is the main microstructure of base metal. Black microstructure is pearlite.

The fusion zone microstructure of electric arc welding that is close to the parent metal is homogeneous ferrite and pearlite, as shown in Fig. 6. The microstructure is quite different from $40 \mathrm{Mn}$ parent metal, which may be caused by that the high temperature of welding changes the microstructure of parent metal into austenite accompanying the smaller size. Then we can get the homogeneous ferrite and pearlite when it is cooled in the air. The microstructure of

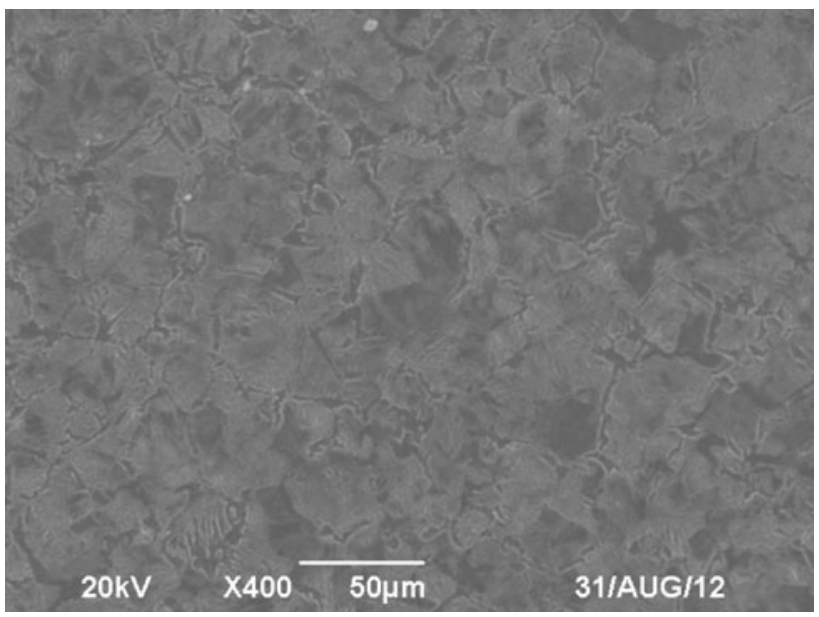

Fig. 5 Microscopic structure of base metal

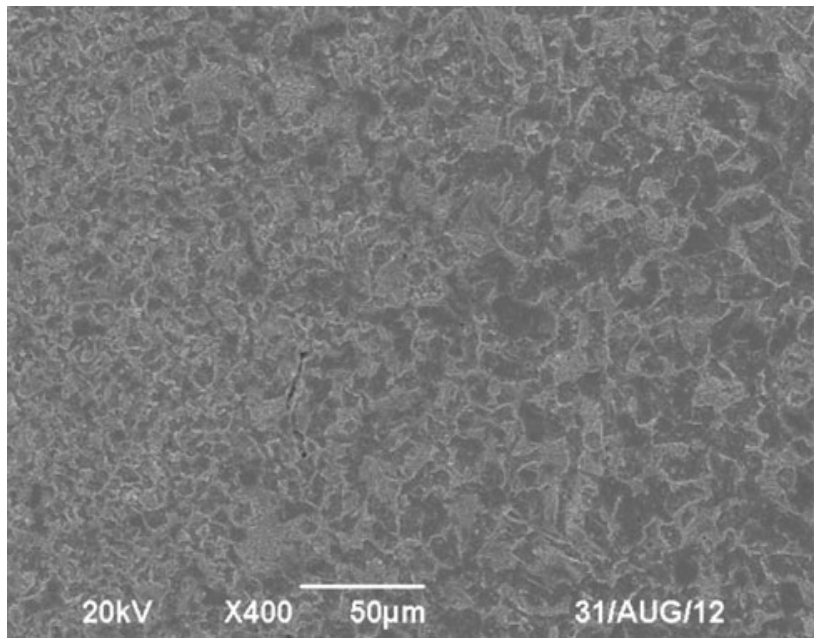

Fig. 6 Fusion zone microscopic structure of electric arc welding

fusion zone which is close to surfacing deposit is black and agglomerated martensite and white retained austenite. That is resulted from that the temperature of fusion zone which is closed to surfacing deposit is very high. Finally a high degree of supercooling is obtained. The circumstance is conducive to the formation of martensite, which hinders the phase transformation of austenite, and residual austenite organization appears in the fusion zone.

Figure 7 shows the fusion zone microscopic structure of $\mathrm{CO}_{2}$ shielded arc welding. The microstructure of fusion zone which is close to parent metal is gray massive ferrite and black pearlite. The transformation of pearlite and some ferrite to autenite happens when soldering, and the others are preserved. After it is cooled, the product of austenitic recrystal is ferrite and pearlite, and the preserved ferrite grows up, which is different from the microstructure of electric arc welding. The microstructure of fusion zone which is close to surfacing deposit is black and 


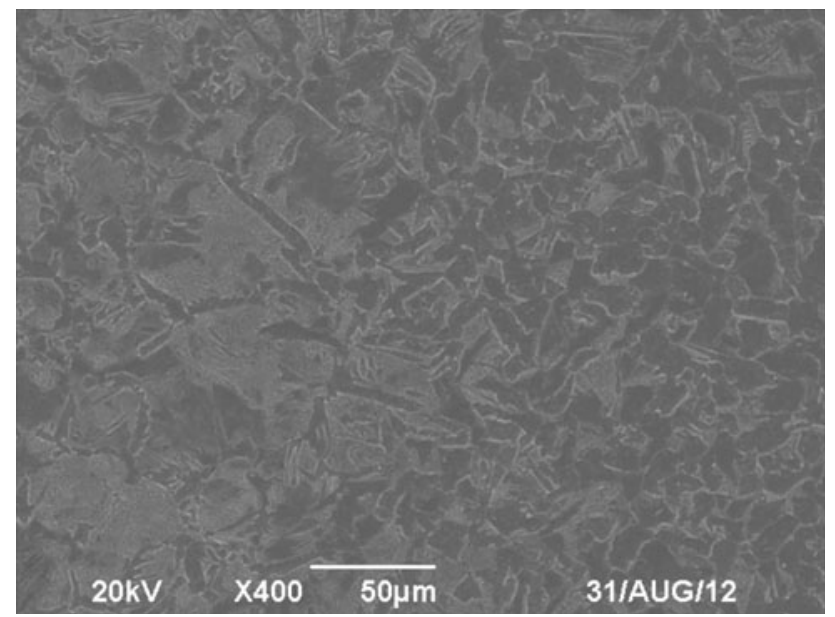

Fig. 7 Fusion zone microscopic structure of $\mathrm{CO}_{2}$ shielded arc welding

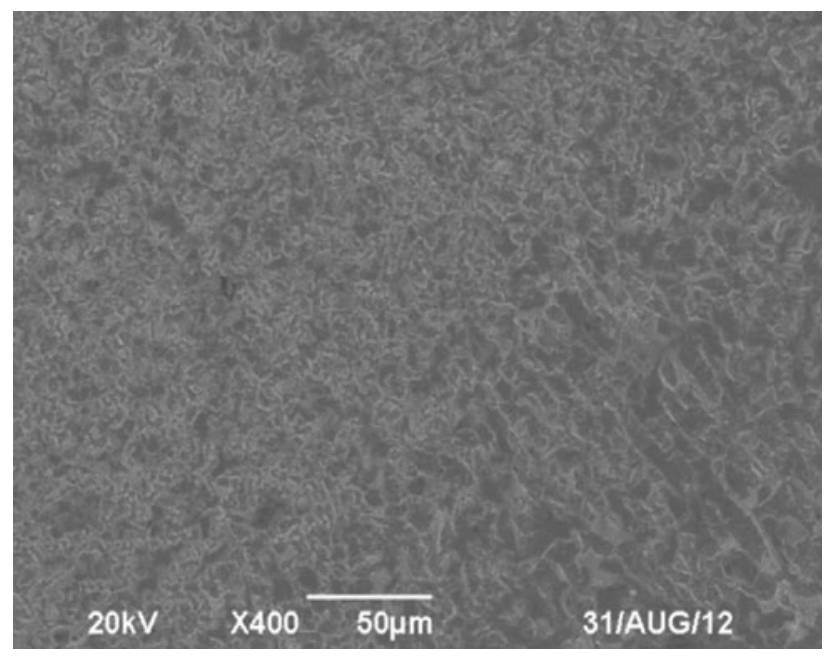

Fig. 8 Fusion zone microscopic structure of argon shielded arc welding

agglomerated martensite and white net retained austenite. Its formation reasons are the same as those of electric arc welding.

The fusion zone microscopic structure of argon shielded arc welding is described in Fig. 8. The microstructure of fusion zone which is close to parent metal is homogeneous ferrite and pearlite. Its formation reasons also are the same as those of electric arc welding. The microstructure of fusion zone which is close to surfacing deposit is black lath martensite and white retained austenite. The lath martensite is different from agglomerated martensite obtained in $\mathrm{CO}_{2}$ shielded arc welding. The main reason may be that dilution rate of $\mathrm{CO}_{2}$ shielded arc welding is higher than that of argon shielded arc welding. It makes that the carbon content of $\mathrm{CO}_{2}$ shielded arc welding become higher than that

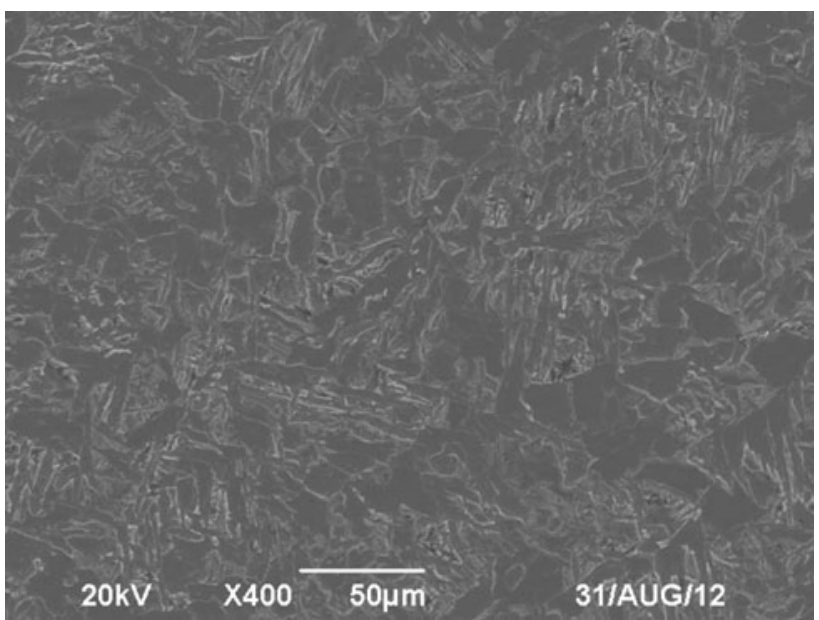

Fig. 9 Outmost layer microscopic structure of electric arc welding

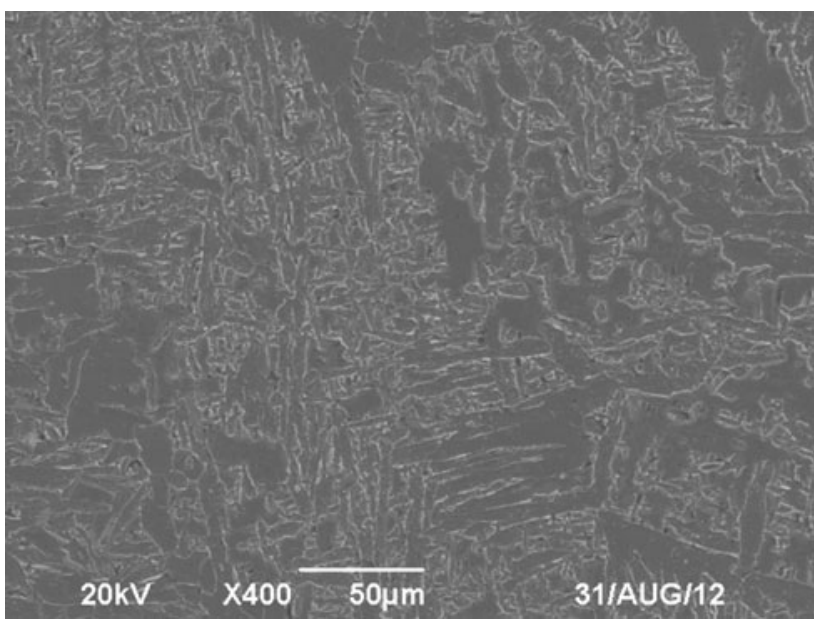

Fig. 10 Outmost layer microscopic structure of $\mathrm{CO}_{2}$ shielded arc welding

of argon shielded arc welding. It is conducive to the formation of martensite.

In conclusion, microstructure of argon shielded arc welding fusion area is more meticulous and uniform than that of electric arc welding and $\mathrm{CO}_{2}$ shielded arc welding.

In order to analyze the relation between residual stress and microscopic structure, microscopic structure of the outmost surfacing layer is detected (see Figs. 9-11).

\subsection{Analysis of residual stress}

The transverse and longitudinal residual stresses of the three welding methods are listed in Tables $2-7$, respectively. Table 8 shows the average value of residual stress of the three welding methods. Minus sign represents pressure stress. 


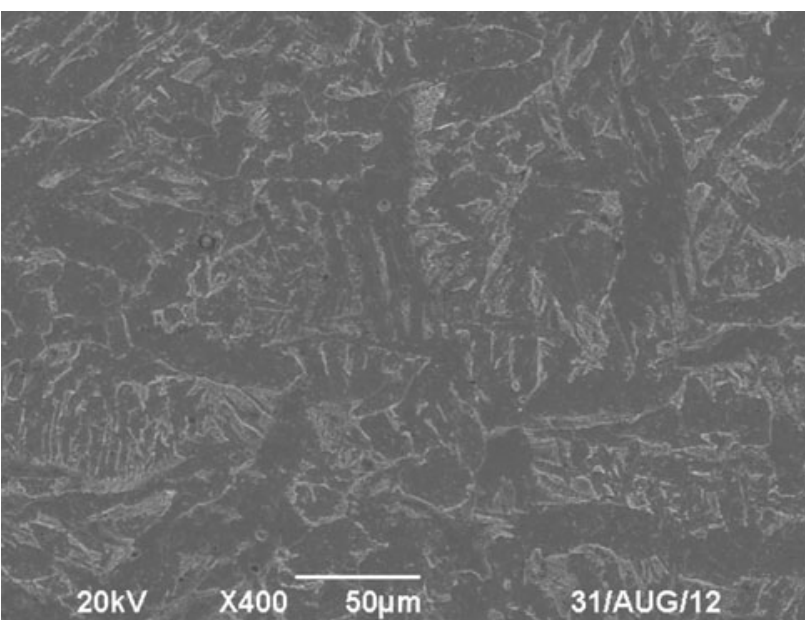

Fig. 11 Outmost layer microscopic structure of argon shielded arc welding

Table 2 Transverse residual stress of weld surface of manual electric arc welding

\begin{tabular}{lcc}
\hline $\begin{array}{l}\text { Numerical } \\
\text { order }\end{array}$ & $\begin{array}{l}\text { Residual } \\
\text { stress/MPa }\end{array}$ & Average value/MPa \\
\hline 1 & 8.20 & $\bar{\sigma}=\left(\sigma_{1}+\sigma_{2}+\cdots+\sigma_{16}\right) / 16$ \\
2 & -25.44 & $=-410.26 / 16$ \\
3 & -3.56 & \\
4 & -70.76 & \\
5 & -27.42 & \\
6 & -33.13 & \\
7 & -21.48 & \\
8 & 4.92 & \\
9 & -8.19 & \\
10 & -60.19 & \\
11 & -35.85 & \\
12 & -14.21 & \\
13 & -21.59 & \\
14 & -23.84 & \\
15 & -22.04 & \\
16 & -55.68 & \\
\hline
\end{tabular}

The safety, reliability and manufacturability of welding structure, welding residual stress are important factors which cause weld crack and fatigue failure [9].

The distribution of residual stress of the three welding methods is displayed in Fig. 12. From Fig. 12, we can observe that the residual stresses of three welding methods are all compressive stress. The transversely residual stresses are basically the same. The longitudinal residual stress (absolute value) of electric arc welding is lower than that of the other two methods, and the longitudinal stress (absolute value) of argon shielded arc welding is slightly larger than that of $\mathrm{CO}_{2}$ shielded arc welding. It is well known that
Table 3 Longitudinal residual stress of weld surface of manual electric arc welding

\begin{tabular}{lcc}
\hline Numerical order & $\begin{array}{l}\text { Residual } \\
\text { stress/MPa }\end{array}$ & Average value/MPa \\
\hline 1 & -50.09 & $\bar{\sigma}=\left(\sigma_{1}+\sigma_{2}+\cdots+\sigma_{16}\right) / 16$ \\
2 & -5.17 & $=-515.65 / 16$ \\
3 & -21.85 & $=-32.23$ \\
4 & -59.04 & \\
5 & -53.66 & \\
6 & 7.82 & \\
7 & -11.95 & \\
8 & -38.95 & \\
9 & -4.54 & \\
10 & -23.11 & \\
11 & -20.38 & \\
12 & -48.00 & \\
13 & -19.75 & \\
14 & -58.36 & \\
15 & -51.60 & \\
16 & -57.02 & \\
\hline
\end{tabular}

Table 4 Transverse residual stress of weld surface of $\mathrm{CO}_{2}$ shielded arc welding

\begin{tabular}{lcc}
\hline Numerical order & $\begin{array}{l}\text { Residual } \\
\text { stress/MPa }\end{array}$ & Average value/MPa \\
\hline 1 & -50.57 & $\bar{\sigma}=\left(\sigma_{1}+\sigma_{2}+\cdots+\sigma_{16}\right) / 16$ \\
2 & -34.64 & $=-383.12 / 16$ \\
3 & -11.65 & $=-23.95$ \\
4 & -9.25 & \\
5 & -24.43 & \\
6 & -47.07 & \\
7 & 3.75 & \\
8 & -9.45 & \\
9 & -7.61 & \\
10 & -8.33 & \\
11 & -33.58 & \\
12 & -37.56 & \\
13 & -28.34 & \\
14 & -18.19 & \\
15 & -27.95 & \\
16 & -38.25 & \\
\hline
\end{tabular}

compressive stress has inhibitory effect on the crack propagation and can improve fatigue strength and toughness. From the perspective of stress, the overlay property of argon shielded arc welding is super to that of electric arc welding and $\mathrm{CO}_{2}$ shielded arc welding.

The compressive stress of deposited metal can be explained from the perspective of metallographic structure. 
Table 5 Longitudinal residual stress of weld surface of $\mathrm{CO}_{2}$ shielded arc welding

\begin{tabular}{lcc}
\hline $\begin{array}{l}\text { Numerical } \\
\text { order }\end{array}$ & $\begin{array}{l}\text { Residual } \\
\text { stress/MPa }\end{array}$ & Average value/MPa \\
\hline 1 & -44.32 & $\bar{\sigma}=\left(\sigma_{1}+\sigma_{2}+\cdots+\sigma_{16}\right) / 16$ \\
2 & -62.09 & $=-729.69 / 16$ \\
3 & -128.41 & \\
4 & -6.12 & \\
5 & -8.09 & \\
6 & -43.09 & \\
7 & -35.83 & \\
8 & 7.27 & \\
9 & -6.54 & \\
10 & -69.28 & \\
11 & -96.83 & \\
12 & -55.76 & \\
13 & -50.65 & \\
14 & -23.32 & \\
15 & -71.48 & \\
16 & -32.15 & \\
\hline
\end{tabular}

Table 6 Transverse residual stress of weld surface of argon shielded arc welding

\begin{tabular}{llc}
\hline Numerical order & $\begin{array}{l}\text { Residual } \\
\text { stress/MPa }\end{array}$ & Average value/MPa \\
\hline 1 & -27.67 & $\bar{\sigma}=\left(\sigma_{1}+\sigma_{2}+\cdots+\sigma_{16}\right) / 16$ \\
2 & -30.12 & $=-387.58 / 16$ \\
3 & -35.9 & $=-24.22$ \\
4 & -19.33 & \\
5 & -38.72 & \\
6 & -26.12 & \\
7 & -31.27 & \\
8 & -39.22 & \\
9 & -23.16 & \\
10 & -18.79 & \\
11 & -13.37 & \\
12 & -22.45 & \\
13 & 2.54 & \\
14 & -2.08 & \\
15 & -38.29 & \\
16 & -23.63 & \\
\hline
\end{tabular}

The transformation of austenite to martensitic takes place at a low temperature, indicating that material is in elastoplastic or elastic state. The volume expansion of metal phase transformation is limited, and phase transformation stress emerges. The stress will reduce residual tension caused by welding thermal field and bring residual compressive stress [10]. From Table 1, we can observe that the
Table 7 Longitudinal residual stress of weld surface of argon shielded arc welding

\begin{tabular}{lcc}
\hline $\begin{array}{l}\text { Numerical } \\
\text { order }\end{array}$ & $\begin{array}{l}\text { Residual } \\
\text { stress/MPa }\end{array}$ & Average value/MPa \\
\hline 1 & -25.29 & $\bar{\sigma}=\left(\sigma_{1}+\sigma_{2}+\cdots+\sigma_{16}\right) / 16$ \\
2 & -76.85 & $=-778.41 / 16$ \\
3 & -12.77 & \\
4 & -18.87 & \\
5 & -10.99 & \\
6 & -19.35 & \\
7 & 1.42 & \\
8 & -11.42 & \\
9 & -40.55 & \\
10 & -69.49 & \\
11 & -119.53 & \\
12 & -130.85 & \\
13 & -84.67 & \\
14 & -18.88 & \\
15 & -35.31 & \\
16 & -105.01 & \\
\hline
\end{tabular}

Table 8 Average value of residual stress of the three methods

\begin{tabular}{lll}
\hline Numerical order & $\begin{array}{l}\text { Transverse } \\
\text { residual } \\
\text { stress/MPa }\end{array}$ & $\begin{array}{l}\text { Longitudinal } \\
\text { residual } \\
\text { stress/MPa }\end{array}$ \\
\hline $\begin{array}{l}\text { Manual electric arc } \\
\text { welding }\end{array}$ & -25.64 & -32.23 \\
CO2 shielded arc welding & -23.95 & -45.42 \\
Argon shielded arc welding & -24.22 & -48.65 \\
\hline
\end{tabular}

content of manganese is $0.70 \%-1.00 \%, 0.31 \%$ and $1.40 \%-1.85 \%$ in base metal, electrode and solder wire, respectively. It is well known that manganese can reduce the austenitic transformation temperature. The microscopic structure (see Figs. 9-11) of outmost surfacing layer confirms the organization of low-temperature phase transition state, indicating that it is possible that low temperature phase transition occurs during the surfacing process, and the compressive stress emerges in outmost surfacing layer. From Table 1, it can be found that the content of manganese of solder wire is far more than that of electrode. If the low-temperature phase transition really occurs, the temperature of austenitic phase transition of two kinds of gas protection welding will be lower than that of electric arc welding, and the effect that phase transformation stress reduces welding thermal stress will be more obvious. The base metal and solder wire of two kinds of gas protection welding are the same and their content of alloying element is consistent, therefore their phase transformation and final residual stress are basically the same. 


\subsection{Analysis of hardness}

Hardness is an overall performance for elasticity, plasticity, strength and toughness. Figures 13-15 show the hardness of three welding methods, in which the hardness of deposited metal is located in the left side of dotted line, and the hardness of base metal is on the other side. Hardness test layers are distributed evenly from outmost welding layer to base metal, and each detection layer is placed per $0.5 \mathrm{~mm}$.

From Figs. 13-15, we can observe that the hardness values of base metal are about $240-250 \mathrm{HV}$, which is consistent with the hardness of $40 \mathrm{Mn}$. By comparing the hardness changing of three kinds of heat affected zone, hardness values of electric arc welding and $\mathrm{CO}_{2}$ shielded arc welding decrease sharply and that of argon shielded arc welding decrease slowly. It is known that metal microstructure is an important element for hardness [11]. From Figs. 6-8, the structure morphology of electric arc welding and $\mathrm{CO}_{2}$ shielded arc welding are of apparent difference, and that of argon shielded arc welding has less difference.

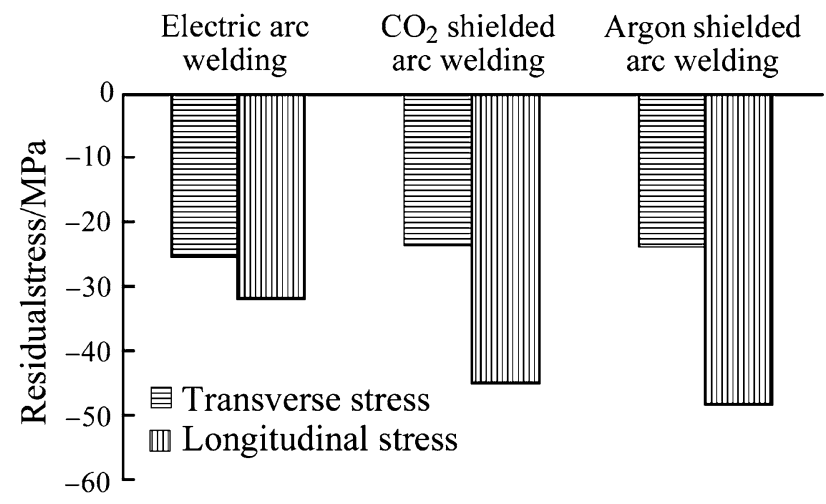

Fig. 12 Distribution of transverse and longitudinal stress

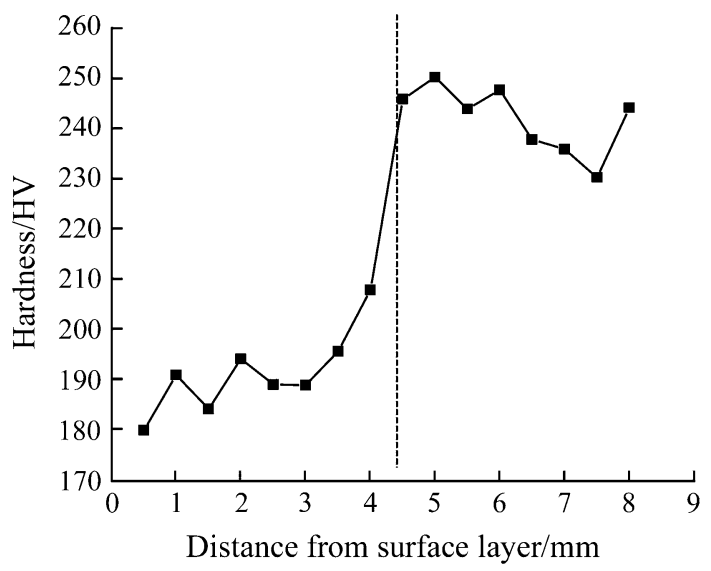

Fig. 13 Hardness of electric arc welding

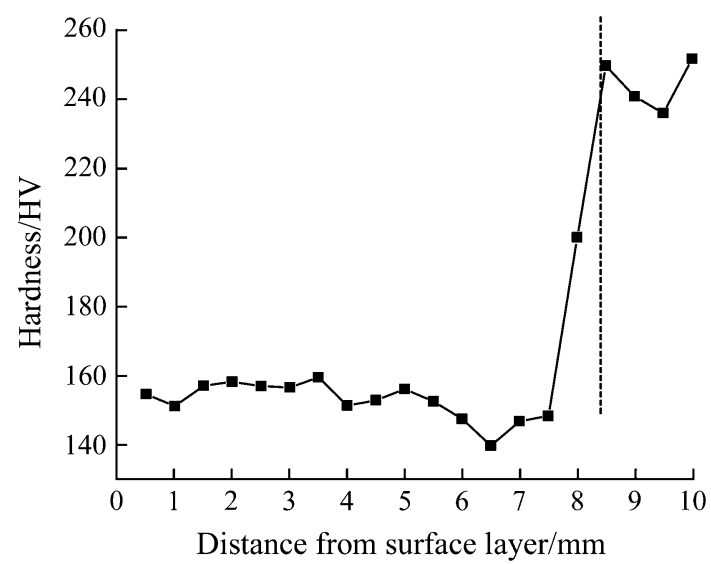

Fig. 14 Hardness of $\mathrm{CO}_{2}$ shielded arc welding

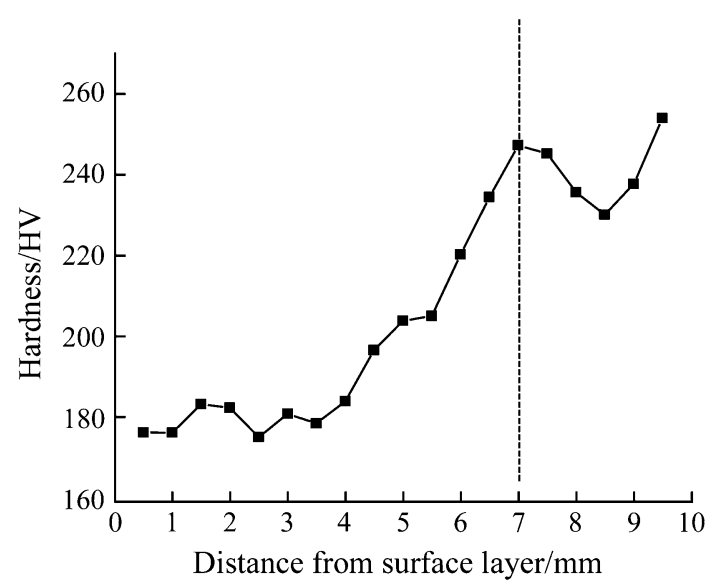

Fig. 15 Argon shielded arc welding

The different microstructure morphology contributes to the different hardness variation. Figures 13-15 also shows that the hardness of outmost layers of electric arc welding and argon shielded arc welding is about $180 \mathrm{HV}$, and that of $\mathrm{CO}_{2}$ shielded arc welding is about $155 \mathrm{HV}$. The difference can also be explained by structure morphology. The outmost layers of electric arc welding and argon shielded arc welding have much more plate martensite, while that of $\mathrm{CO}_{2}$ shielded arc welding has much more lath martensite and austenite, as can be observed from Figs. 9-11. It is known that the hardness of plate martensite is higher than that of lath martensite, and the hardness of austenite is low. Therefore, the hardness of electric arc welding and argon shielded arc welding is higher than that of $\mathrm{CO}_{2}$ shielded arc welding.

In addition, it is known that the hardness of welding material is usually too high to lathe. Therefore, the low hardness material is chosen in this experiment on the basis of weldability. The shortage of the test is that the hardness values of deposited metal are all lower than that of base 
metal. It increases the risk of screw failure, though it is beneficial to lathe. In order to solve the problem and make the hardness reach or slightly exceed that of base metal, the appropriate local heat treatment or more appropriate welding material is a good choice.

\section{Conclusions}

(i) Microstructure of fusion area of argon shielded arc welding is more meticulous and uniform than that of electric arc welding and $\mathrm{CO}_{2}$ shielded arc welding.

(ii) Residual stresses of outmost layer of the three weld methods are all compressive stress. The compressive stress (absolute value) of electric arc welding is lower than that of other two methods. The residual stress of $\mathrm{CO}_{2}$ shielded arc welding and argon shielded arc welding are basically the same.

(iii) Hardness values of heat affected zone of electric arc welding and $\mathrm{CO}_{2}$ shielded arc welding decreases sharply than that of argon shielded arc welding. The hardness values of deposited metal are all lower than that of base metal.

(iv) Argon shielded arc welding is an effective way to repair the failure thread.

Acknowledgments It was supported by the National Basic Research Program of China (Grant No. 2011CB013406), Theories of Decision Support and Comprehensive Evaluation for a Remanufacturing System and Hefei AAM Automotive Driveline and Chassis System Co., Ltd, the Remanufacture of Rear Axle. Professor Shou-Xu Song, colleagues and enterprise technicians have made significant contributions to the experimental and numerical work covered in this paper, and these are acknowledged with thanks.

\section{References}

1. Xu BS (2010) Recent progress of remanufacture industry and technology in China. Therm Spray Technol 2:1-6

2. Xie ZH (2011) Efforts to achieve new breakthroughs in the development of remanufacturing industry. China Surf Eng 24:1-3

3. Lund RT, Hauser WM (2010) Remanufacturing: an American perspective. In: Proceedings of 5th international conference on responsive manufacturing-green manufacturing, New Jersey, IET.1-6

4. Steinhilper R, Brent A (2003) Saving product lives in global and local remanufacturing networks: a scientific and commercial work report and an outlook. In: 3rd International symposium on environmentally conscious design and inverse manufacturing, IEEE, New York, pp 297-302

5. Zhang WD, Cui JB (2005) Repairing instances with manual arc resurfacing welding. Equip Technol 2:33-34

6. Sun X (2008) The repair of final axle shaft threads of TY320 bulldozer. Oper Maint 39:65

7. Tang ZW (2007) Exploration of repair methods for driving axle housing of Dongfeng dump truck. Auto Maint Repair 11:73-74

8. Lakshminarayanan AK, Shanmugam K, Balasubramanian V (2009) Effect of welding processes on tensile and impact properties, hardness and microstructure of AISI $409 \mathrm{M}$ ferritic stainless joints fabricated by duplex stainless steel filler metal. J Iron Steel Res Int 16:66-72

9. Xu WG, Burdekin FM (1998) Effects of residual stresses on constraint and fracture behavior of wide plates. Math Phys Eng Sci 454:2505-2528

10. Wang WX, Huo LX, Zhang YF et al (2002) Investigation on phase stress and its application to improving fatigue strength of welding joints. Chin J Mech Eng 38:65-68

11. Hou J, Peng QJ, Takeda Y et al (2010) Microstructure and mechanical property of the fusion boundary region in an alloy 182-low alloy steel dissimilar weld joint. J Mater Sci 45:5332-5338. doi:10.1007/s10853-010-4581-6 